\title{
Weight-Related Stigma as a Predictor of Self-Disclosure Patterns in Women ${ }^{\delta}$
}

\author{
Denise M. Polk*, ${ }^{*}$ and Gwen A. Hullman ${ }^{2}$ \\ ${ }^{1}$ West Chester University, Main Hall, 5th Floor, West Chester, PA 19383, USA; ${ }^{2}$ United States, University of Nevada, \\ Reno MS 0229 Reno, NV 89557, United States
}

\begin{abstract}
Research suggests that overweight/obese people face stigma. A measure of weight-related stigma was developed, adapted from the HIV stigma measure (Berger, Ferrans, \& Lashley, 2001). A CFA confirmed the measure's internal consistency. Using privacy management theory as a framework, participants $(N=199)$ completed a self-report survey that included a hypothetical conversational partner profile. Regression analysis and independent sample $t$-tests helped answer hypotheses about the ways weight-related stigma affect disclosure as well as how weight affects selfdisclosure and attraction. Attraction to partner and weight-related stigma significantly predicted overall self-disclosure ratings. Implications for obesity research, privacy management, and stigma are discussed.
\end{abstract}

Keywords: Stigma, obesity, self-disclosure, health.

\section{INTRODUCTION}

Obesity in the United States is on the rise (Center for Disease Control and Prevention; CDC (2009a). According to the CDC (2009a), the terms overweight and obesity are labels for weight ranges greater than what is generally considered healthy for a given height. In 2008, only Colorado had a prevalence of obesity less than $20 \%$, and 32 states had a prevalence equal to or greater than 25\% (CDC, 2009b). People whose body mass index (BMI) exceeds 25 are labeled as overweight, and people whose BMI exceeds 30 are considered obese (CDC, 2009a). Some people, however, use the terms interchangeably (Smith, Schmoll, Konik, \& Oberlander, 2007). For the purposes of this study, we distinguished only between people in the "normal" weight range versus people who would be considered "overweight/obese" by these criteria.

\section{Stigma}

Attitudes about people who are obese largely are negative. Negative and socially undesirable attributes that people assign (Goffman, 1963) to people who are obese include: (a) anti-fat bias where existing negative attitudes towards people who are obese often result in discriminatory acts and (b) obesity stigma which is the resulting social disapproval tied to such stereotypes (Lewis, \& Van Puyembroeck, 2008). As a result, stigma is an issue of social injustice and disempowerment (Scheyett, 2005) for which people who are obese might seek support -- requiring interpersonal interaction and most likely disclosure about the stigmatized experience.

\footnotetext{
*Address correspondence to this author at the West Chester University, Main Hall, 5th Floor, West Chester, PA 19383, USA; Tel: 610-436-2180; Fax: 610-436-3046; E-mails: dpolk@wcupa.edu; dmpolk@kent.edu ${ }^{\delta}$ This project was partially supported through a University of Nevada College of Liberal Arts Scholarly and Creative activities Grant.
}

\section{Communication Privacy Management Theory}

Communication privacy management theory (Petronio, 1991) considers the role of self-disclosure, which is defined as the personal information people verbally reveal about themselves (Delerga, Metts, Petronio, \& Margulis, 1993). Petronio developed communication privacy management theory to explain the way people regulate the flow of private information. Communication privacy management has been used in a wide variety of contexts such as friendships (Wilson, Roloff, \& Carey, 1998), family communication (Afifi, 2003; Caughlin, Huston, \& Houts, 2000; Thorson, 2009), computer-mediated communication (Metzger, 2007), living in a nursing home (Petronio, \& Kovach, 1997) and disclosing HIV status (Greene, Derlega, Yep, \& Petronio, 2003).

Communication privacy management differs from earlier studies on self-disclosure (e.g., Jourard, 1964). First, whereas Jourard (1964) suggested that more disclosure is desirable, communication privacy management considers that people value disclosure, but they also value privacy and recognize serious risks associated with disclosure (Morr, Serewicz, \& Petronio, 2007). Competent self-disclosure is dialectical because it involves communicators balancing both interactants' needs for intimacy and privacy (Dindia, 1994). Petronio's (1991) tenets of communication privacy management theory also differ from Jourard because they separate the ideas of disclosure and intimacy development (Morr, Serewicz, \& Petronio, 2007). Communication privacy management also involves several layers that consider beliefs about private information and: ownership, control, boundaries, and the consequences of making another person a co-owner of it.

\section{Rationale}

Communication privacy management provides a helpful framework in which to study how weight-related stigma 
affects women's self-disclosure. First, although some research suggests individuals are rewarded for engaging in high levels of self-disclosure (Barker \& Benton, 1994), studies using privacy management have found people may be punished for their self-disclosure. Women may be susceptible to the privacy-disclosure dilemmas associated with weight-related stigma because women provide more personal self-disclosure than men, and they are also more likely to be the target of self-disclosure (Dindia \& Allen, 1992; Dolgin, Meyer, \& Schwartz, 1991). In addition, women tend to be held to stricter standards regarding their weight (Blaine \& Williams, 2004). Relatively little is known about disclosure decisions made by people who are obese.

The weight of both conversational partners can influence conversation. For example, both overweight and normal weight nurses expressed concern about offering advice to patients about eating better and exercising more (Brown \& Thompson, 2007). Nurses with a high BMI expressed concern about being judged by patients or by being seen as poor role models whereas nurses with a low BMI feared they would be perceived as unauthentic. In addition some people have distinct terminology preferences when discussing weight-related issues (Wadden \& Didle, 2003).

Bliss (2006) argued that attitudes surrounding obesity lead to less discussion of women's weight-related stigma experiences and perhaps a greater sense that they are the only ones "failing" at attempts to lose weight. Whereas people commonly discuss diet strategies and success rates, "... it is unusual to hear obese people discuss what it is like for them to be overweight, and still more rare to hear them describe their weight control failures" (Rogge, Greenwald, \& Golden, 2004, p. 301). This appears to be important for buffering weight-related stigma. For example, Puhl and Brownell (2003) suggested that discussing stigmatized experiences might reduce stigma because people question social consensus about bias. In addition, invoking empathy from discrimination stories reduced bias against obesity (Teachman, Gapinski, Brownell, Rawlins, \& Jeyaram, 2003). Tucker, Martz, Curtin, and Bazzini (2007) used confederates in mixed BMI female dyads to engage in "fat talk" and found that conversational partners followed the norm of reciprocity by attempting to match each other's body presentation style, but the discussion of weight might have been avoided by some conversational partners had not the confederate initiated it.

People have multiple, and often conflicting, goals surrounding self-disclosure (Dindia, 1994), and they use past experiences to predict potential future outcomes. Considering the mixed and negative messages about people who are obese, talking about weight is face-threatening. Dindia's ideas about the intrapersonal relationship between self-disclosure and stigma are intriguing. Stigmatized individuals engage in a dialectical process whereby they cyclically engage in a need to preserve face so as not to induce shameful feelings and in a need to confide in others to seek help (Limandri, 1989). Women who are obese constantly may feel a loss of face. As a result, these women experience a greater number of situations where they are unsure of what type of identity to project.

In addition, according to the premises of communication privacy management, people are expected to learn self- disclosure norms through socialization (Morr Serewicz \& Petronio, 2007). If women have been "punished" for their weight-related disclosure in the past, the norm of reciprocity, an overarching principle of face (Goffman, 1963), might seem counterintuitive. This elicits privacy dilemmas suggested by Petronio (2007) and may impact disclosure decisions in order to serve as self-protection. Because people who experience repeated stigma go to great lengths to avoid situations that may induce stigma (Myers \& Rosen, 1999) the following hypothesis can be tested:

H1: Stigma will be a negative predictor of weight-related disclosure made in conversation.

Gaining and giving social support often requires selfdisclosure. Moreover, effective support is related to effective coping with weight-related stigma (Panchankis, 2007). However, similar to communication privacy management predictions regarding risks for both nondisclosure and disclosure, people are aware of risks associated with soliciting and giving support (Goldsmith, 2004). Effective support is critical for effective weight management. Even when people express desire to lose weight, they need professional and social support to be successful (Bidgood \& Buckroyd, 2005). Ineffective support may contribute to the onset of obesity and/or may worsen weight-related health concerns (Okun \& Keith, 1998).

Women tend to be the primary seekers of health information for themselves and for other family members (Warner \& Procaccino, 2004; Wuest, 2000). Women also use formal networks (e.g., doctors) as well as informal networks, (e.g., other friends, often female) to seek healthrelated information (Harris \& Dewdney, 1994). Because people who are obese stigmatize excess weight as much as people who are not overweight (Lewis \& Van Puymbroeck, 2008; Schwartz, Vartanian, Nosek, \& Brownell, 2006), people who are obese develop very little sense of in-group identity and support (Crandall, 1994; Crocker, Voelkl, Testa, \& Major, 1991). In addition, "obesity stigma-by-association" may create the perception of support unavailability (Hebl \& Mannix, 2003). These missed opportunities to gain support and to cope with stigma because of hesitation to engage in weight-related self-disclosure result in limited or unavailable access to other women as support resources. Derlega, Lovejoy, and Winstead (1998) claimed that people with HIV experience a tension between the wish to disclose information in order to obtain support and the need to conceal information to protect against discrimination, rejection, and gossip. Obese women also may experience similar tensions. Therefore, the following hypotheses test the relationship between weight and self-disclosure:

$\mathrm{H} 2$ : Participants in the "normal" weight category will be less likely to make weight-related disclosures to overweight conversational partners than to normal weight partners.

H3: Overweight participants will be less likely than normal weight women to make weight-related disclosures to conversational partners regardless of partner weight.

Communication privacy management suggests that judgments about weight also impact other characteristics of the target of disclosure which in turn impact disclosure. A person's appearance is especially important in the beginning stages of a relationship (Rosenfeld, Stewart, Stinnett, \& 
Jackson, 1999). Berg and Archer (1983) stated that "few would contest the assertion that we disclose more to who we like" (p. 269), and this makes sense since Broder (1982) claimed that the relationship between liking and attraction has received "widespread empirical support" (p. 303). Given the tendency for people to rate "normal" weight people as more attractive than people who are obese (Chen, 1997; Knapp \& Hall, 1997; Legenbauer, Vocks, Shäfer, SchüttStromel, Hiller, Wagner, \& Vogele, 2009; Lin, 1998), we expect that people would like more attractive targets more and therefore disclose more information to them. As a result, the following hypotheses will test attraction and weight and disclosure:

H4: Regardless of participant weight, participants will rate obese conversational partners as less attractive.

H5: Attraction to conversational partner will be a positive predictor of the types of disclosure made in conversation.

Anti-fat bias not only predicts body image, but also may predict the way individuals value themselves (Friedman, Reichmann, Costanzo, Zell, Ashmore, \& Musante, 2005). There seems to be a more robust relationship between one's perceived weight and self-esteem than between one's actual weight and self-esteem (Miller \& Downey, 1999). Heightened self-awareness results from disclosure (Duval \& Wicklund, 1972), but increased self-awareness about undesirable aspects of oneself also can negatively impact self-esteem (Derlega et al., 1993). Thus, people might feel worse about their weight when faced with decisions about weight-related disclosure simply because it heightens their awareness both of their personal feelings toward their weight as well as the potential weight-related stigma. In this case, self-esteem might mediate the perception that weight-related topics should be avoided.

Stigma also impacts the relationship between obesity and self-esteem. For example, heavy women exhibit internalized weight bias (Durso \& Latner, 2008). Ultimately, these selfesteem issues impact the ability to form close relationships (Bidgood \& Buckroyd, 2005), judgments about a person's worthiness as a partner (Boles \& Latner, 2009), and relational commitment (Boles \& Latner, 2009).

People who are obese with lower self-esteem avoid disclosing personal failures because of anticipated negative consequences, whereas those with higher self-esteem anticipate benefits to disclosing personal failures (Cameron, Holmes, \& Vorauer, 2009). Avoiding weight-related topics could be explained by the finding that those who have lower self-esteem tend to ruminate more about potential detrimental consequences of self-disclosure (Afifi \& Caughlin, 2009). Although people who are obese experience lower levels of self-esteem (Friedman, Reichmann, Costanzo, Zell, Ashmore, \& Musante, 2005), Puhl and Heuer (2009) emphasized the need to investigate the influence of stigma on self-esteem and to determine the impact of weightrelated stigma on interpersonal relationships. To find out whether self-esteem influences what types of information are disclosed in conversation, we ask:

RQ1: Is self-esteem a predictor of the types of disclosure made in conversation?

Thus, preliminary findings about weight-related stigma and disclosure decisions of women can be used to develop a subsequent test of actual interactions. Ultimately, the present study can serve as a springboard to advance Petronio's (2007) goals for communication privacy management such as determining how to change communication situations or how to create a new system when people might face privacy dilemmas, privacy violations, and trust mistakes. Specifically, weight-related stigma might trigger people to examine the relational consequences of talking about their weight. This line of thinking would provide additional support for one of Jacoby's (2005) dimensions of stigma, disruptiveness (the degree to which the stigma interferes with social interactions). If women encounter disruption caused by preoccupation with word choice and content of self-disclosure of weight-related issues, then weight-related stigma negatively affects and disrupts social interaction. Thus, these situations might lead to rigid boundaries that allow for little or no disclosure (Greene, 2000). Little or no disclosure impedes relational development and social support opportunities, which can result in social isolation. Isolation is especially dangerous for those dealing with a medical condition leading to possible health complications.

\section{MATERIALS AND METHODOLOGY}

\section{Participants}

Adult females $(N=199)$ were recruited to participate in this study. Recruitment sites included a mid-size Eastern university campus, a mid-size Western university campus, and various groups in which women participate (for example, a group of mothers of preschoolers). Participants received $\$ 10$ cash for their participation, which took approximately 20 minutes of their time. The majority of participants was Caucasian $(n=166 ; 83.4 \%)$. Other ethnic groups included African American $(n=11 ; 5.5 \%)$, Latino $(n=7 ; 3.5 \%)$, Asian American $(n=5 ; 2.5 \%)$, and "Other" $(n=3 ; 1.5 \%)$. Participants' ages ranged from 18 to 81 with a mean age of 42 and standard deviation of 14.77. Some women ( $n=36 ; 18.1 \%$ belonged to a weight-related or exercise group such as Weight Watchers $(n=13 ; 6.5 \%)$, Curves $(n=13 ; 6.5 \%)$, Jazzercise $(n=8 ; 4.0 \%)$, or "Other" $(n=9 ; 4.5 \%)$.

\section{Procedures}

Participants were recruited by placing flyers on campus or locations where the groups met. When potential participants contacted the investigators, they arranged a mutually agreeable time to complete the survey. As part of the information sheet, participants read, "This questionnaire contains questions about your reactions to appearances, conversational topics, and demographic information" and "You are being asked to participate because you interact with other people, and you create impressions of others." Participants completed questions about themselves, their own experiences, and reactions to a hypothetical conversational partner. To avoid fatigue or order effects, two versions of the questionnaire packets were administered randomly where items appeared in reverse order.

\section{Instruments}

\section{Weight-related Stigma}

Berger et al. (2001) tested the HIV Stigma Scale. This multidimensional measure consists of 40 Likert-type items 
on four different factors (personalized stigma, disclosure concerns, negative self-image, and concern with public attitudes about people with HIV). Berger et al. reported an overall coefficient alpha of .96 , a test-retest correlation of .92 , and subscale alphas ranging from .90 to .93 . Significant relationships with several related constructs such as selfesteem $(r=-.60)$, depression $(r=.63)$, and social integration, ( $r=.65)$ established construct validity (Berger et al., 2001).

Both HIV and weight-related stigma are health-related concerns, providing an appropriate link between the HIV items and weight-related stigma. Some items required some wording changes. For example, "Some people act as if it's my fault I have HIV" became "Some people act as though my weight is my fault." Other items did not require any wording changes such as "I feel set apart, isolated from the rest of the world." Because these wording changes could affect reliability and validity, we conducted a pilot study to test the items. After item analysis, 15 items were retained (see results section for criteria about decisions to reduce scale items). Participants responded to the 15 Likert-type statements $(1=$ strongly disagree to $5=$ strongly agree $)$.

\section{Self-Esteem}

To measure self-esteem we used the Rosenberg SelfEsteem Scale (Rosenberg, 1965). The 10 Likert-type items (1 = strongly agree to $4=$ strongly disagree) assess a person's overall evaluation of his or her worthiness as a human being (Rosenberg, 1979). Rosenberg reported test-retest correlations (.82 to .88) and Cronbach's alphas (.77 to .88; see Blascovich \& Tomaka, 1993; Rosenberg, 1986).

\section{Photo Profile Manipulation}

The development of stimulus materials was loosely based on Hebl and Turchin (2005). To develop the stimulus materials, four photographs represented potential conversational partners (two obese and two nonobese). The photographs depicted white females with short to shoulder length hair who all displayed positive facial expressions in order to help isolate the influence of weight. Thirty-six participants responded to an additional page (at the end of the questionnaire) where they indicated their opinion of the weight of all four of the pictured women on a Likert-type scale $(1=$ very underweight to $5=$ very overweight $)$. The mean scores for the obese photographs were both 4.15 and for the nonobese photographs were 2.48 and 2.62. Paired sample $t$-tests corrected for multiple comparisons using the Bonferroni correction showed that the two obese photographs were not perceived as significantly different $(t(35)=00, p=1.00)$, nor were the nonobese photos $(t(35)=$ $.90, p=.373)$. However, participants perceived the obese photos as significantly different from the nonobese photos $(t(35)=-17.86, p=.000 ; t(35)=-14.35, p=.000 ; t(35)=$ $13.182 ; p=.000 ; t(35)=14.44, p=.000)$, demonstrating validity of the stimulus materials as examples of overweight and normal weight women.

The same written profile accompanied each of the four photographs. The profile included the woman's name (Judy), her occupation (a schoolteacher), and her age range (between the ages of 35-45). The profile served to provide depth of character to the photograph to facilitate answering the remaining questions in the survey. The characteristics of the profile were held constant across conditions to isolate the influence of weight.

\section{Self-Disclosure}

To measure self-disclosure we used items developed by Jourard (1968, 1971a, 1971b). Jourard (1971a, 1971b) reported satisfactory reliability for several versions. Through repeated testing, Jourard (1971a) established validity by showing significant relationships between self-disclosure and liking and interpersonal attraction. Jourard (1971a) reported that other researchers have established predictive validity between past disclosure and willingness to disclose. In most of the studies, Jourard asked participants either to check items they would be willing to discuss, or he asked participants to answer using the following responses: " $0=$ have told the other person nothing about this aspect of me," "1 = have talked in general terms about this," "2 = have talked in full and complete detail about this item to the other person," or "X = have lied or misrepresented myself to the other person so that he has a false picture of me" (counted/coded as zeros). Participants responded to this information about one or more specific targets (e.g., mother or spouse).

Jourard's (1971b) scale items are topics appropriate to assess disclosure in this study because of the breadth of topics they include. For example, items inquire about hobbies, reading preferences, travel experiences, etc. Because Jourard asserted that all disclosure is good for relationship development (which differs from communication privacy management), it was important to get participants to assess their desirability to disclose about each topic to Judy rather than simply checking their willingness to disclose to Judy using a Likert-type scale ( $1=$ highly desirable topic to $5=$ highly undesirable topic $)(\alpha=$ .86). The average for the weight and appearance-related items were subtracted from the average score for the entire scale to compute a difference score. The difference score represents a measure of willingness to disclose weight and appearance-related items compared against a baseline level self-disclosure level for the participants.

\section{Attraction}

McCroskey and McCain (1974) developed the 15-item Interpersonal Attraction Scale (IAS) as a three dimensional construct consisting of social, task, and physical. They reported internal reliabilities for the 15-item Likert-type scale $(1=$ strongly disagree to $7=$ strongly agree $)$ ranging from .81 to .86 . Other researchers also have reported adequate reliability (Wheeless, Frymier, \& Thompson, 1992). Construct validity also has been established by Duran and Kelly (1988) and Burgoon and Hale (1988). For the purposes of this study, participants responded only to the five items representing social attraction since the present study involves a potential friendly conversation (e.g., "I think she could be a friend of mine.")

\section{Obesity}

To measure obesity, we calculated BMI. According to the CDC (2009a), BMI is appropriate for this study because it correlates with most people's amount of body fat. In the demographic section, participants completed questions about 
their height, weight, age, ethnicity, and whether they participated in a weight/diet-related support group. Calculating BMI involves weight corrected for height and has been widely used for assessing weight (Blaine \& Williams, 2004). Other available calculations are more invasive than participants self-reporting height and weight. Results ranged from 16.82 to $45.19(M=26.04, S D=6.07)$. Nearly $45 \%$ the participants met the BMI criterion reported by the CDC (2007) for being either overweight $(>25)$ or obese $(>30)$.

\section{RESULTS}

\section{Study One}

To pilot the weight-related stigma items, 114 female volunteer participants responded to the stigma items and the Rosenberg Self-Esteem Scale (Rosenberg, 1965). Of the participants, 46 were undergraduate students and 68 were in a "mothers of preschoolers" group. Because of some wording changes, we did not predict a priori that the weightrelated stigma items would produce four factors like the original measure. An exploratory factor analysis using principal components analysis helped determine the factor structure. Although the initial solution produced eight factors accounting for $75 \%$ of the variance, after applying a 60/40 loading rule, a single factor emerged. After eliminating double loaded items, a 15 -item solution accounted for $57 \%$ of the variance. Results suggested sufficient reliability $(\alpha=$ $.96)$, and validity with a significant negative relationship with self-esteem $(r=-.63, p<.01)$.

\section{Study Two}

Reliability analyses suggested sufficient reliabilities for: weight-related stigma ( $\alpha=.89)$, self-esteem $(\alpha=.84)$, overall self-disclosure $(\alpha=.86)$, and social attraction $(\alpha=.77)$. CFA using AMOS 6.0 (Arbuckle, 2006) helped to determine the internal consistency of the stigma, attraction, and self-esteem scales. Final items were retained based on the guidelines of Bentler (1992), Browne and Cudeck, (1993), Hu and Bentler (1999), and Kline (2005).

Correlation and regression analysis provided answers to the hypotheses. Table 1 displays the correlations among the variables. All relevant analyses account for three different operational definitions of self-disclosure as a measure of disclosure of: (a) only weight-related topics, (b) the weightrelated items divided by baseline self-disclosure (adjusted self-disclosure), and (c) a baseline indicator of how much participants disclose on a number of topics (baseline selfdisclosure).

Regression analyses helped answer the first and fifth hypotheses. The results partially support the first hypothesis, which predicted that stigma would be a negative predictor of disclosure. Of the three types of self-disclosure, stigma served as a negative predictor only for adjusted selfdisclosure (See Tables 2, 3 and 4). Less stigma predicted more disclosure. The fifth hypothesis centered around the influence of social attraction on self-disclosure. Attraction did not significantly predict weight-related self-disclosure or adjusted self-disclosure (See Tables 2 and $\mathbf{3}$ ). However, social attraction served as a positive predictor of baseline self-disclosure (See Table 4). This regression also helped to answer the research question about the role of self-esteem as a predictor of types of disclosure. Results suggest that selfesteem did not have a significant effect on any of the types of self-disclosure made in this study (See Tables 2, 3 and 4).

For hypotheses two, three, and four, independent sample $t$-tests helped answer the predictions. After selecting only to analyze participants in the normal weight category (BMI < 25), results did not support hypothesis two; that these participants would engage in less weight-related selfdisclosure to overweight than to normal weight

Table 1. Correlations Among Variables

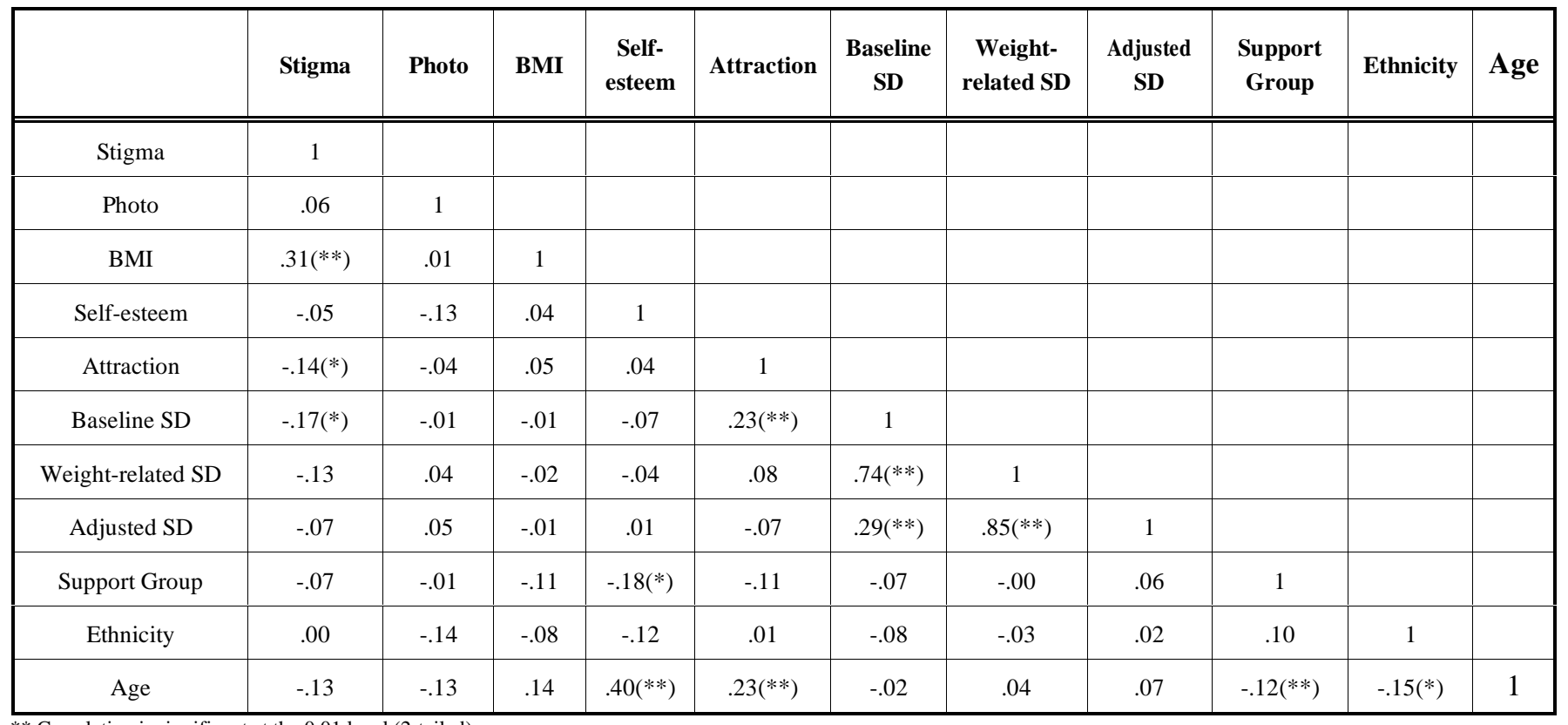

** Correlation is significant at the 0.01 level (2-tailed)

* Correlation is significant at the 0.05 level (2-tailed). 
Table 2. Regression Analysis for Weight-Related Self-Disclosure

\begin{tabular}{|c|c|c|c|c|c|}
\hline & B & SE B & $\beta$ & $t$ & $p$ \\
\hline (Constant) & 3.331 & .763 & & 4.364 & .000 \\
\hline Age & .002 & .005 & .026 & .308 & .758 \\
\hline Ethnicity & -.021 & .088 & -.019 & -.242 & .809 \\
\hline Support group & -.080 & .183 & -.034 & -.440 & .661 \\
\hline Stigma & -.011 & .007 & -.129 & -1.618 & .107 \\
\hline BMI & .002 & .012 & .011 & .136 & .892 \\
\hline Self-esteem & -.041 & .080 & -.042 & -.522 & .603 \\
\hline Attraction & .056 & .068 & .064 & .817 & .415 \\
\hline Photo & -.039 & .141 & -.021 & -.279 & .781 \\
\hline
\end{tabular}

Note: $N=199$

Table 3. Regression Analysis for Adjusted Self-Disclosure

\begin{tabular}{|c|c|c|c|c|c|}
\hline (Constant) & 3.605 & .433 & & 8.334 & .000 \\
\hline Ethnic & -.064 & .050 & -.094 & -1.274 & .204 \\
\hline Support Group & -.148 & .104 & -.106 & -1.433 & .154 \\
\hline BMI & .002 & .007 & .025 & .330 & .742 \\
\hline Self-esteem & -.028 & .045 & -.048 & -.619 & .537 \\
\hline Attraction & .120 & .039 & .234 & 3.116 & .002 \\
\hline
\end{tabular}

Note: $N=199$

conversational partners. More specifically, this prediction was not true for any of the types of self-disclosure: (a) baseline self-disclosure $=t(101)=1.78, p=.08$ (one-tailed), $M=3.35, S D=0.59$, (b) weight-related self-disclosure = $t(101)=0.478, p=.63$ (one-tailed), $M=3.03, S D=0.89$ (c) or adjusted self-disclosure $=t(101)=-.378, p=.71$ (onetailed), $M=0.90, S D=0.19$. Regarding hypothesis three, that obese participants would be less likely than their normal weight counterparts to make weight-related self-disclosures regardless of conversational partner weight, results did not support this hypothesis for any of the types of selfdisclosure: (a) baseline self-disclosure $=t(197)=-0.71, p=$ .48 (one-tailed), $M=3.25, S D=0.60$, (b) weight-related selfdisclosure $=t(197)=-0.256, p=.80$ (one-tailed), $M=2.99$, $S D=0.99$ (c) or adjusted self-disclosure $(t(101)=0.023, p=$ .98 (one-tailed), $M=0.91, S D=0.22$. Hypothesis four predicted that regardless of participant weight, obese conversational partners would be rated as less socially attractive than nonobese conversational partners. Results did not support this hypothesis $(t(197)=0.57, p=.57$ (onetailed), $M=5.30, S D=0.99)$.

\section{DISCUSSION}

In the present investigation, we sought to determine the effects of weight-related stigma on women's self-disclosure patterns using communication privacy management as a framework. As Petronio (2000; 2002) explained, privacy is actually a dialectical tension balanced by self-disclosure. People can make attempts to suppress the saliency of weightrelated appearance by avoiding certain conversational topics. If someone feels the need to keep weight information private, s/he most likely will avoid those topics in conversation. Ironically, disclosing the information could be one way to reduce weight-related stigma (Puhl \& Brownell, 2003).

The reason for avoiding these topics most likely stems from weight-related stigma. Both Limandri (1989) and Herek and Glunt (1988) claimed that stigma results in a 
Table 4. Regression Analysis for Baseline Self-Disclosure

\begin{tabular}{|c|c|c|c|c|c|}
\hline (Constant) & .915 & .174 & & 5.271 & .000 \\
\hline Ethnicity & .011 & .020 & .041 & .535 & .594 \\
\hline Stigma & -.001 & .002 & -.072 & -.902 & .369 \\
\hline BMI & .000 & .003 & .012 & .149 & .882 \\
\hline Self-esteem & -.001 & .018 & -.003 & -.039 & .969 \\
\hline Attraction & -.018 & .015 & -.090 & -1.144 & .254 \\
\hline
\end{tabular}

preference for avoidance because it carries shame and discredit. In the case of weight-related stigma, both normal weight and overweight individuals hold implicit stereotypes that those who are obese are lazy and bad (Schwartz et al., 2006). The same sample also reported a willingness to make sacrifices (e.g., their fertility) rather than be obese. Perhaps those who feel weight-related stigma internalize weight and appearance so much so that it engulfs their identity.

Sontag (1989) argued that having a chronic illness changes a person's identity. As a result, disclosure leads to feelings of vulnerability and may result in self-identity protection rules. The finding that stigmatized individuals prefer to talk about non-weight-related topics over weightrelated topics supports this argument.

These feelings seem counterbalanced by attraction to their conversational partner. Attitudes of potential friendship and social attraction resulted in more disclosure. These findings support Altman and Taylor's (1973) claims that people rate relationships more favorably and will progress to the next level when they forecast future rewards. For those who feel weight-related stigma, attraction toward others provides avenues for interpersonal support, even from those who do not have weight issues themselves.

Overweight or obese people tend to be more critical of others who are overweight or obese than people in a normal weight range (Brown \& Thompson, 2007). As a result, these avoidance attempts are true even with in-group members, who normally would be a source of information sharing and support. Thus, people who are overweight themselves would be likely to avoid disclosing information about weight to maintain privacy and control. However, the target of disclosure's weight did not elicit a difference in selfdisclosure patterns.

The lack of significance might suggest that these prior findings of negative attributions and criticism are not always founded. People seem at least still willing to engage in conversation and to self-disclose, despite the other person's physical appearance. As a result, this study provides some related evidence to support the idea that people's weight does not negatively impact the quality of the interpersonal relationships (Carr \& Friedman, 2006).

Level of self-esteem also does not seem to influence willingness to disclose weight-related information. Despite reason to believe that self-esteem influences disclosure choices about failures (Cameron et al., 2009), we did not also assess whether participants deemed their weight as a personal failure. Perhaps it was not considered a personal failure for our participants, whose scores for self-esteem were unrelated to scores for weight-related stigma.

Aside from support for communication privacy management for self-disclosure patterns of weight-related information, the current investigation also provides a promising new measure for weight-related stigma. Given the growing problem of obesity in society and the need for social support for those dealing with weight-related stigma, future research addressing this issue is imminent. The stigma measure we adapted from the HIV stigma measure (Berger et al., 2001) provides a standardized measure with acceptable psychometric properties for future research.

\section{Limitations}

As with all studies, some limitations should be noted. For example, the four photographs used were uncopyrighted internet photos of four different women. Even though the manipulation check established that participants judged correctly the photos intended to represent nonobese women and obese women, participants' answers could not be attributed wholly to weight assessments. Perhaps taking one photograph of the same nonobese woman and manipulating it to make her appear obese (or vice versa) would strengthen the study.

In addition, all methodologies involve trade-offs. In this study, some limitations of using self-reported data should be acknowledged. First, it is possible that participants lied about their weight; however, this seemed less invasive than weighing participants and measuring their height. Second, having participants self-report about "Judy" could be very 
different from their actual behavior, so future research could involve actual interactions.

\section{CONCLUSION}

Whereas this study only measured the topics that people selected they would be willing to discuss, future research could focus on the reasons people give for their disclosure decisions. Derlega et al.'s (1998) study about people with HIV revealed 11 different reasons for disclosing HIV status as well as seven reasons for keeping HIV status private. Even though weight is not concealable, people can exercise control over weight-related topics. Future studies might uncover the reasons people who are obese cite for their disclosure decisions.

In addition, future research could focus on the actual language used in conversation. Because Brown and Thompson (2007) found that nurses showed particular sensitivity to word choices about weight-related issues, it is possible that other people use different language when they discuss weight-related issues depending on their own and their interaction partner's weight. Smith, Waldorf, and Trembath (1990) suggested that terms such as voluptuous and full-figured are attempts to develop more positive thinking about larger women, and it is possible that differences exist depending on the terminology utilized.

Finally, research suggests that whereas women are held to more rigid standards for weight and appearance, many men increasingly experience weight-related stigma (Hebl \& Turchin, 2005). Including men in future studies also should be a consideration for future research.

Obesity is a hot button topic right now. Health experts are attempting to address the issue by educating the public about nutrition choices and activity levels. However, the prevalence of weight-related stigma clearly affects how people think about obesity which, in turn, affects how people talk about weight-related issues. Barriers to disclosure may occur when people experience stigma. These barriers suppress information sharing and support. This issue becomes more problematic when people within an in-group stigmatize other in-group members more harshly than outgroup members. Learning more about the nature of weightrelated communication topics is an essential component to providing people with tools to make the changes necessary to lose weight successfully and to maintain a healthy weight.

\section{DISCLOSURE}

An earlier version of this manuscript was presented at the 2008 National Communication Association Convention.

\section{REFERENCES}

Afifi, T. D. (2003). "Feeling caught" in stepfamilies: Managing boundary turbulence through appropriate communication privacy rules. Journal of Social and Personal Relationships, 20, 729-755.

Afifi, W. A., \& Caughlin, J. P. (2009). A close look at revealing secrets and consequences that follow. Communication Research, 33, 467-488.

Altman, I., \& Taylor, D. (1973). Social Penetration: The Development of Interpersonal Relationships. New York: Holt, Rinehart and Winston.

Arbuckle, J. L. (2006). AMOS (Version 6.0) [Computer software]. Chicago: SmallWaters Corporation.
Barker, B. L., \& Benton, C. L. (1994). The Ethics of Feminist Selfdisclosure. In Carter K. \& Presnell M. (Eds.), Interpretive Approaches to Interpersonal Communication (pp. 219-246). Albany, NY: State University of New York Press.

Bentler, P. M. (1992). On the fit of models to covariances and methodology to the bulletin. Psychological Bulletin, 112, 400-404.

Berg, J. H., \& Archer, R. L. (1983). The disclosure-liking relationship: Effects of self-perception, order of disclosure, and topical similarity. Human Communication Research, 10, 269- 281.

Berger, B. E., Ferrans, C. E., \& Lashley, F. R. (2001). Measuring stigma in people with HIV: Psychometric assessment of the HIV stigma scale. Research in Nursing \& Health, 24, 518-529.

Bidgood, J., \& Buckroyd, J. (2005). An exploration of obese adults' experience of attempting to lose weight and to maintain a reduced weight. Counseling and Psychotherapy Research, 5, 221-229.

Blaine, B., \& Williams, Z. (2004). Belief in the controllability of weight and attributions to prejudice among heavyweight women. Sex Roles, $51,79-84$.

Blascovich, J., \& Tomaka, J. (1993). Measures of self-esteem. In Robinson, J. P., Shaver, P. R., \& Wrightsman, L. S., (Eds.), Measures of Personality and Social Psychological Attitudes (3rd ed., pp. 115160). Ann Arbor: Institute for Social Research.

Bliss, K. (2006). Redefine the problem so it has a solution. Health at Every Size, 20, 17-23.

Boyes, A. D., \& Latner, J. D. (2009). Weight stigma in existing romantic relationships. Journal of Sex and Marital Therapy, 35, 282-293.

Broder, S. (1982). Liking, own disclosure, and partner disclosure in female roommates. Journal of Social Psychology, 117, 303-304.

Brown, I., \& Thompson, J. (2007). Primary care nurses' attitudes, beliefs, and own body size in relation to obesity management. Journal of Advanced Nursing, 60, 535, 543.

Browne, M. W., \& Cudek, R. (1989). Single sample cross-validation indices for covariance structures. Multivariate Behavioral Research, 24, 445-455.

Burgoon, J. K., \& Hale, J. L. (1988). Nonverbal expectancy violations: Model elaboration and application to immediacy behaviors. Communication Monographs, 55, 58-79.

Cameron, J. J., Holmes, J. G., Vorauer, J. D. (2009). When self-disclosure goes awry: Negative consequences of revealing personal failures for lower self-esteem individuals. Journal of Experimental Social Psychology, 45, 217-222.

Carr, D., \& Friedman, M. A. (2006). Body weight and the quality of interpersonal relationships. Social Psychology Quarterly, 69, 127149.

Caughlin, J. P., Huston, T. L., \& Houts, R. M. (2000). How does personality matter in marriage? An examination of trait anxiety, interpersonal negativity, and marital satisfaction. Journal of Personality \& Social Psychology, 78, 326-336.

Center for Disease Control. (2007). BMI - Body mass index. Retrieved February, 12, 2008 from http://www.cdc.gov/nccdphp/dnpa/bmi/adult_BMI/about_adult_BMI.htm\#Interpreted

Center for Disease Control and Prevention (2009a). Overweight and obesity. Retrieved January 28, 2009 from http://www.cdc.gov/nccdphp/dnpa/obesity/defining.htm

Center for Disease Control and Prevention (2009b). Overweight and obesity. Retrieved August 20, 2009 from http://www.cdc.gov/obesity/data/trends.html

Chen, N. Y. (1997). On physical attractiveness stereotyping in Taiwan: A revised sociocultural perspective. Journal of Social Psychology, 137, 117-124.

Crandall, C. S. (1994). Prejudice against fat people: Ideology and selfinterest. Journal of Personality and Social Psychology, 66, 882894.

Crocker, J., Voelkl, K., Testa, M., \& Major, B. (1991). Social stigma: The affective consequences of attributional ambiguity. Journal of Personality and Social Psychology, 60, 218-228.

Derlega, V. J., Lovejoy, D., \& Winstead, B. A. (1998). Personal Accounts on Disclosing and Concealing HIV-Positive Test Results: Weighing the Benefits and Risks. In Derlega, V. J., \& Barbee, A. P., (Eds.), HIV and Social Interaction (pp. 147-164). Thousand Oaks, CA: Sage.

Delerga, V. J., Metts, S., Petronio, S., \& Margulis, S. T. (1993). SelfDisclosure. Thousand Oaks, CA: Sage.

Dindia, K. (1994). The Intrapersonal-Interpersonal Dialectical Process of Self-Disclosure. In Duck, S., (Ed.), Dynamics of Relationships (pp. 27-57). Thousand Oaks, CA: Sage. 
Dindia, K., \& Allen, M. (1992). Sex-differences in self-disclosure: A metaanalysis. Psychological Bulletin, 112, 106-124.

Dolgin, K. G., Meyer, L., \& Schwartz, J. (1991). Effects of gender, target's gender, topic, and self-esteem on disclosure to best and midling friends. Sex Roles, 25, 311-329.

Duran, R. L., \& Kelly, L. (1988). The influence of communicative competence on perceived tasks, social, and physical attraction. Communication Quarterly, 36, 41-49.

Durso, L. E., \& Latner, J. D. (2008). Understanding self-directed stigma: Development of the weight bias internalization scale. Obesity, 16, S80-6.

Duval, S., \& Wicklund, R. A. (1972). A Theory of Objective SelfAwareness. New York: Academic Press.

Friedman, K. E., Reichmann, S. K., Costanzo, P. R., Zell, A., Ashmore, J. A., \& Musante, G. J. (2005). Weight stigmatization and ideological beliefs: Relation to psychological functioning in obese adults. Obesity Research, 13, 907-916.

Goffman, E. (1963). Stigma. Englewood Cliffs, NJ: Prentice-Hall.

Goldsmith, D. (2004). Communicating Social Support. Cambridge, UK: Cambridge University Press.

Greene, K. (2000). Disclosure of Chronic Illness Varies by Topic and Target: The Role of Stigma and Boundaries in Willingness to Disclose. In Petronio, S., (Ed.), Balancing the Secrets of Private Disclosures (pp. 123-135). Mahwah, NJ: Erlbaum.

Greene, K., Derlega, V. J., Yep, G. A., \& Petronio, S. (2003). Privacy and Disclosure of HIV in Interpersonal Relationships: A Sourcebook for Researchers and Practitioners. Mahwah, NJ: LEA Publishers.

Harris, R. M., \& Dewdney, P. (1994). Barriers to Information: How Formal Help Systems Fail Battered Women. Westport, CT: Greenwood Press.

Hebl, M. R., \& Mannix, L. M. (2003). The weight of obesity in evaluating others: A mere proximity effect. Personality and Social Psychology Bulletin, 29, 28-38.

Hebl, M. R., \& Turchin, J. M. (2005). The stigma of obesity: What about men? Basic and Applied Social Psychology, 27, 267-275.

Herek, G. M., \& Glunt, E. K. (1988). An epidemic of stigma: Public reactions to AIDS. American Psychologist, 43, 886-891.

Hu, L. T., \& Bentler, P. M. (1999). Cutoff criteria for fit indexes in covariance structure analysis: Conventional criteria versus new alternatives. Structural Equational Modeling: A Multidisciplinary Journal, 6, 1-55.

Jacoby, A. (2005). Epilepsy and social identity: The stigma of a chronic neurological disorder. Lancet Neurology, 4, 171-178.

Jourard, S. M. (1964). The Transparent Self: Self-Disclosure and WellBeing. New York: Van Nostrand Reinhold.

Jourard, S. M. (1968). Disclosing Man to Himself. New York: Van Nostrand Reinhold Company.

Jourard, S. M. (1971a). Self-disclosure: An Experimental Analysis of the Transparent self. New York: Wiley.

Jourard, S. M. (1971b). The transparent self (Rev ed.). New York: Van Nostrand Reinhold.

Kline, R. B. (2005). Principles and Practice of Structural Equation Modeling (2nd ed.). New York: Guilford.

Knapp, M. L., \& Hall, J. A. (1997). Nonverbal Communication in Human Interaction (4th ed.). Fort Worth, TX: Harcourt Brace.

Legenbauer, T., Vocks, S., Shäfer, C. Schütt-Stromel, S., Hiller, W., Wagner, C., \& Vogele, C. (2009). Preference for attractiveness and thinness in a partner: Influence of internalization of the thin ideal and shape/weight dissatisfaction in heterosexual women, heterosexual men, lesbians, and gay men. Body Image, 6, 228-234.

Lewis, S. T., \& Van Puymbroeck, M. (2008). Obesity-stigma as a multifaceted constraint to leisure. Journal of Leisure Research, 40, 574-588.

Limandri, B. J. (1989). Disclosure of stigmatizing conditions: The discloser's perspective. Archives of Psychiatric Nursing, 3, 69-78.

Lin, C. A. (1998). Use of sex appeals in prime-time television commercials. Sex Roles, 38, 461-475.

McCroskey, J. C., \& McCain, T. A. (1974). The measurement of interpersonal attraction. Speech Monographs, 41, 261-266.

Metzger, M. J. (2007). Communication privacy management in electronic commerce. Journal of Computer-Mediated Communication, 12, 127.

Miller, G. T., \& Downey, K. T. (1999). A meta-analysis of heavyweight and self-esteem. Personality and Social Psychology Review, 5, 68-84.

Morr Serewicz, M. C., \& Petronio, S. (2007). Communication Privacy Management Theory. In Whaley, B., \& Samter, W., (Eds.),
Explaining Communication: Contemporary Theories and Exemplars (pp. 257-273). Mahwah, NJ: Lawrence Erlbaum Associates.

Myers, A., \& Rosen, J. C. (1999). Obesity stigmatization and coping: Relation to mental health symptoms, body image, and self-esteem. International Journal of Obesity, 23, 221-230.

Okun, M.A., \& Keith, V. M. (1998). Effects of positive and negative social exchanges with various sources on depressive symptoms of younger and older adults. Journals of Gerontology: Series B: Psychological Sciences and Social Sciences, 53, 4-20.

Panchankis, J. E. (2007). The psychological implications of concealing a stigma: A cognitive-affective-behavioral model. Psychological Bulletin, 133, 328-345.

Petronio, S. (1991). Communication boundary management: A theoretical model of managing disclosure of private information between marital couples. Communication Theory, 1, 311-335.

Petronio, S. (2000). The Boundaries of Privacy: Praxis of Everyday Life. In Petronio, S., (Ed.), Balancing the Secrets of Private Disclosures (pp. 37-50). Mahwah, NJ: Erlbaum.

Petronio, S. (2002). The Boundaries of Privacy: Dialectics of Disclosure. New York: State University of New York Press.

Petronio, S. (2007). Translational research endeavors and the practices of communication privacy management. Journal of Applied Communication Research, 35, 218-222.

Petronio, S., \& Kovach, S. (1997). Managing privacy boundaries: Health providers' perceptions of resident care in Scottish nursing homes. Journal of Applied Communication Research, 25, 115-131.

Puhl, R. M., \& Brownell, K. D. (2003). Psychosocial origins of obesity stigma: Toward changing a powerful and pervasive bias. Obesity Reviews, 4, 213-227.

Puhl, R. M., \& Heuer, C. A. (2009). The stigma of obesity: A review and update. Obesity, 17, 941-964.

Quinn, D. M., \& Crocker, C. (1999). When ideology hurts: Effects of belief in the Protestant ethic and feeling overweight on the psychological well-being of women. Journal of Personality and Social Psychology, 77, 402-414.

Rogge, M. M., Greenwald, M., \& Golden, A. (2004). Obesity, stigma, and civilized oppression. Advances in Nursing Science, 27, 301-315.

Rosenberg, M. (1965). Society and the Adolescent Self-Image. Princeton, NJ: Princeton University Press.

Rosenberg, M. (1979). Conceiving the Self. New York: Basic Books.

Rosenberg, M. (1986). Self-Concept from Middle Childhood Through Adolescence. In Suls, J., \& Greenwald, A. G., (Eds.), Psychological Perspectives on the Self (Vol. 3, pp. 107-135). Hillsdale, NJ: Erlbaum.

Rubin, Z., Hill, C. T., Peplau, L. A., \& Dunkel-Schetter, C. (1980). Selfdisclosure in dating couples: Sex roles and the ethic of openness. Journal of Marriage and the Family, 42, 305-317.

Scheyett, A. (2005).The mark of madness: Stigma, serious mental illness, and social work. Social Work in Mental Health: The Journal of Behavioral and Psychiatric Social Work, 3, 79-97.

Schwartz, M. B., Vartanian, L. R., Nosek, B. A., \& Brownell, K. D. (2006). The influence of one's own body weight on implicit and explicit anti-fat bias. Obesity, 14, 440-447.

Shapiro, J. R., King, E. B., \& Quinones, M. A. (2007). Expectations of obese trainees: How stigmatized trainee characteristics affect trainee effectiveness. Journal of Applied Psychology, 92, 239-249.

Smith, C. A., Schmoll, K., Konik, J., \& Oberlander, S. (2007). Carrying weight for the world: Influence of weight descriptors on judgments of large-sized women. Journal of Applied Social Psychology, 5, 989-1006.

Smith, J. E., Waldorf, V. A., \& Trembath, D. L. (1990). "Single white male looking for thin, very attractive ..." Sex Roles, 23, 675-685.

Sontag, S. (1989). Illness as Metaphor; and, AIDS and its Metaphors. New York: Anchor Books Doubleday.

Teachman, B., Gapinski, K. D., Brownell, K. D., Rawlins, M., \& Jeyaram, S. (2003). Demonstrations of implicit anti-fat bias: The impact of providing causal information and evoking empathy. Health Psychology, 22, 68-78.

Thorson, A. R. (2009). Adult children's experiences with their parent's infidelity: Communication protection and access rules in the absence of divorce. Communication Studies, 60, 32-48.

Tucker, K. L., Martz, D. M., Curtin, L. A., \& Bazzini, D. G. (2007) Examining "fat talk" experimentally in a female dyad: How are women influenced by another woman's body presentation style? Body Image, 4, 157-164. 
Wadden, T. A., \& Didle, E. (2003). What's in a name? Patients' preferred terms for describing obesity. Obesity Research, 11, 1140-1146.

Warner, D., \& Procaccino, J. D. (2004). Toward wellness: Women seeking health information. Journal of the American Society for Information Science and Technology, 55, 709-730.

Wheeless, L. R., Frymier, A. B., \& Thompson, C. A. (1992). A comparison of verbal output and receptivity in relation to attraction and communication satisfaction in interpersonal relationships. Communication Quarterly, 38, 372-387.

Wilson, L. L., Roloff, M. E., \& Carey, C. M. (1998). Boundary rules: Factors that inhibit expressing concerns about another's romantic relationship. Communication Research, 25, 618-640.

Wuest, J. (2000). Negotiating with helping systems: An example of grounded theory evolving through emergent fit. Qualitative Health Research, 10, 51-70.

Received: September 01, 2010

Revised: November 29, 2010

Accepted: December 03, 2010

(C) Polk and Hullman.; Licensee Bentham Open.

This is an open access article licensed under the terms of the Creative Commons Attribution Non-Commercial License (http://creativecommons.org/licenses/by-nc/3.0/) which permits unrestricted, non-commercial use, distribution and reproduction in any medium, provided the work is properly cited. 